\section{Cellulitis of the right thigh, with gas}

\author{
F M Braeunling MRCP P M Mackey FRCS \\ C Wright FRCR O E Klimach MD FRCS \\ D N Ramanaden MRCP
}

J R Soc Med 2003;96:553-554

Cellulitis involving the lower limb is a common cause of admission to hospital. In instances where cellulitis affects the thigh and groin region, anorectal causes should be sought.

\section{CASE HISTORY}

A woman of 69 was admitted after four weeks of rigors, low backache and anorexia. In addition her right hip had been painful for three weeks. There had been no change of bowel habit or abdominal pain. Three days before admission she had been started on trimethoprim by her general practitioner for a possible urinary tract infection. The medical history included hypertension, a pleomorphic salivary gland adenoma (excised one year previously) and rheumatoid arthritis. She was taking co-codamol, lansoprazole, lisinopril and prednisolone (15 mg once daily); she had recently stopped taking methotrexate.

On examination she was pyrexial (temperature $38.4^{\circ} \mathrm{C}$ ) and mildly jaundiced. Her abdomen was soft and nontender, but the right thigh was erythematous, warm and swollen on the anteromedial aspect from just below the inguinal ligament to the mid thigh. Haemoglobin was $11.5 \mathrm{~g} / \mathrm{dL}$, white cell count $18.0 \times 10^{9} / \mathrm{L}$, bilirubin $41 \mu \mathrm{mol} / \mathrm{L}$. Cellulitis was diagnosed and she was started on intravenous benzylpenicillin $1.2 \mathrm{~g}$ four times daily and flucloxacillin $1 \mathrm{~g}$ four times daily. After 48 hours the thigh was slightly less erythematous but the fever persisted. Blood cultures were negative as were antistreptolysin titres. The treatment was changed to intravenous metronidazole $500 \mathrm{mg}$ three times daily and clindamycin $600 \mathrm{mg}$ four times daily and hyperbaric oxygen. After a further three days the cellulitis had spread over the whole thigh, her temperature was $39^{\circ} \mathrm{C}$ and there was evidence of an underlying soft tissue collection with crepitus. An ultrasound scan revealed gas in the soft tissues from the thigh to the ankle, confirmed by a plain X-ray. On clinical examination of the abdomen and perineum there was still no evident septic focus. Drainage of the thigh abscess

Departments of General Surgery, Medicine, and Radiology, Glan Clwyd Hospital, Rhyl, North Wales LL18 5UJ, UK

Correspondence to: F M Braeunling yielded a large volume of foul smelling gas and pus, and the incision was extended from the groin to the knee. Most of the pus was subcutaneous; a small amount extended between the muscle groups but there was no evidence of myonecrosis. A tract was seen to be extending extraperitoneally up the femoral canal, with pus coming from above. A drain was placed up the femoral canal and the thigh wound was left open. On culture the pus gave a mixed growth of coliforms, anaerobic flora, streptococcus species and Pseudomonas aeruginosa. A CT scan showed extensive diverticular disease and a gas collection in the region of the right femoral canal closely related to a loop of bowel (Figure 1). At this stage faeces began to emerge from the thigh wound. At laparotomy there was a perforated diverticular mass in the right iliac fossa which had tracked down the femoral canal without contamination of the peritoneal cavity. A Hartmann's procedure was performed, with resection of about $15 \mathrm{~cm}$ of diseased sigmoid colon. After sixteen days she underwent debridement of the right thigh wound which was then closed with deep tension sutures. A lymphocutaneous fistula developed but this settled spontaneously. Five months later the colostomy was reversed without complications.

\section{COMMENT}

A possible cause of the gas tracking in the soft tissue was necrotizing fasciitis. However, no debridement of necrotic tissue was necessary during the initial procedure; moreover, necrotizing fasciitis is usually associated with a thin brown exudate rather than a large amount of frank pus. ${ }^{1}$ A largebowel origin is more likely, and the perforation might have occurred several weeks earlier, with partial walling off in the right iliac fossa. The patient was insistent about her lack

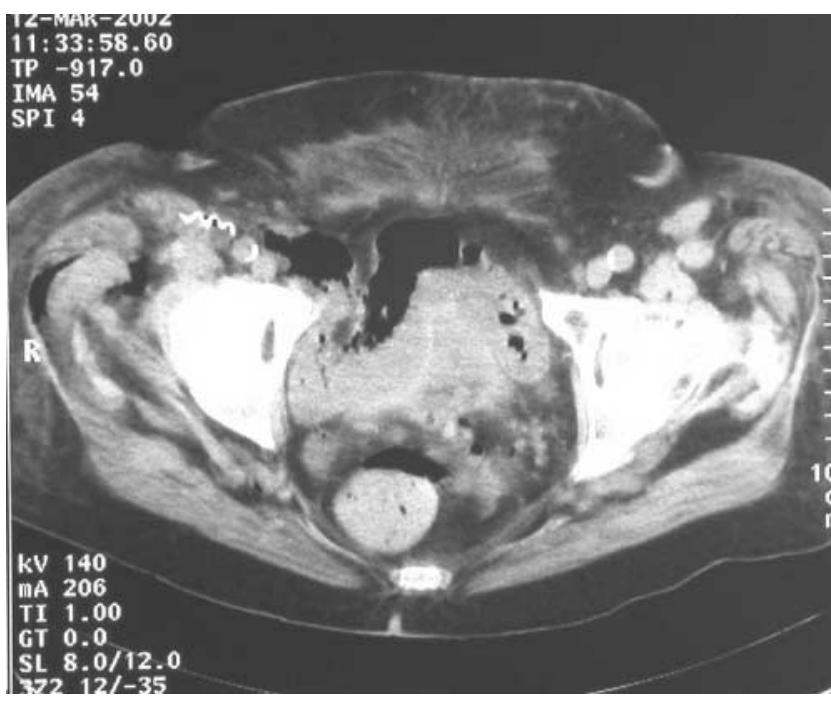

Figure 1 Axial CT slice at level of hip joint, demonstrating air in soft tissue and tracking in the femoral canal 
of gastrointestinal symptoms, but the manifestations could have been limited by the steroid she was taking.

Although femoral hernias usually contain omentum or small bowel, occasionally they contain appendix, caecum, testicle, ovary, a Meckel's diverticulum or a caecal diverticulum. ${ }^{2}$

Previous workers have described necrotizing fasciitis of the abdominal wall secondary to a strangulated femoral hernia containing a perforated sigmoid diverticulum in the presence of a rectosigmoid cancer, though this involved the left femoral canal. ${ }^{3}$ Necrotizing fasciitis has also been described in the abdominal wall over the right iliac fossa secondary to perforation of a sigmoid diverticulum. ${ }^{4} \mathrm{We}$ have not found any previous report of a perforated sigmoid diverticulum presenting with cellulitis and abscess formation in the right thigh.

\section{REFERENCES}

1 Nichols RL, Florman S. Clinical presentations of soft-tissue infections and surgical site infections. Clin Infect Dis 2001;33(suppl 2):84-93

2 Naunton-Morgan RM, Maw A. Solitary caecal diverticulum strangulated in a femoral hernia. Br J Surg 1996;83:1547

3 Conn IG, Martin DL, La Ferla G. Necrotising fasciitis secondary to a strangulated femoral hernia containing a perforated sigmoid diverticulum. J R Col Surg Edinb 1996;31:91-2

4 Harrison BJ. Perforated sigmoid diverticulum with necrotizing fascilitis of the abdominal wall. $J R$ Soc Med 1981;74:625-6

\section{'Aggressive keloid': a severe variant of familial keloid scarring}

\author{
Ardeshir Bayat MB MRCS ${ }^{1,3,4}$ Guyan Arscott MB FRCS 2 \\ William E R Ollier BSc $\mathrm{PhD}^{3}$ \\ Mark W J Ferguson BSc PhD ${ }^{4}$ \\ D Angus McGrouther MD FRCS ${ }^{1}$
}

J R Soc Med 2003;96:554-555

Keloid scars are nodular skin lesions that in severe forms resemble neoplasms and cause much physical and mental distress. Attempts at treatment can make them worse.

'Department of Plastic and Reconstructive Surgery, South Manchester University Hospital Trust, Manchester, UK; ${ }^{2}$ Department of Plastic and Reconstructive Surgery, University of West Indies, Mona, Kingston, Jamaica; ${ }^{3}$ Centre for Integrated Genomic Medical Research and ${ }^{4}$ Division of Cell, Immunology and Development, School of Biological Sciences, University of Manchester, Manchester, UK

Correspondence to: Mr A Bayat, Department of Burns, Plastic and Reconstructive Surgery, Wythenshawe Hospital, South Moor Road, Wythenshawe, Manchester M23 9LT, UK

E-mail: ardeshir.bayat@man.ac.uk

\section{CASE HISTORIES}

\section{Case 1}

A woman aged 21, of black Jamaican origin, had experienced keloid scarring from her early teens after minor trauma. Now she was much troubled by multiple large scars on the back, deltoid regions, lower legs, arms, upper buttocks and chest. Her sister and her brother also had keloid scarring. Treatments had included surgical excision, radiotherapy and steroid injections; none of these had given lasting benefit, and the recurrent lesions were worse, causing physical and psychological distress.

\section{Case 2}

A woman of 44, of black Jamaican origin, had experienced multiple keloid scarring from the age of 8. Existing scars had continued to grow and new ones had developed even after minor abrasions. When seen by us she had extensive keloid scars on her chest (Figure 1), arms, back, lower legs, pubis, and buttock. Most of the scars were sessile, in parts lobulated and of hard consistency. The scars were functionally disabling as well as emotionally distressing. In the past, unsuccessful treatments had included pressure garments, silicone gels, steroid injections, surgical excisions, and superficial radiotherapy. The only other medical history of note was recent diagnosis of a uterine fibroid. Having left Jamaica as a child she was unsure of her family history, but her father was believed to have been affected by keloid scarring. So too was her only daughter, who had multiple but less severe lesions than our patient.

\section{Case 3}

A 90-year-old man of black Jamaican origin sought advice about multiple keloid scars in his armpits and on his lower

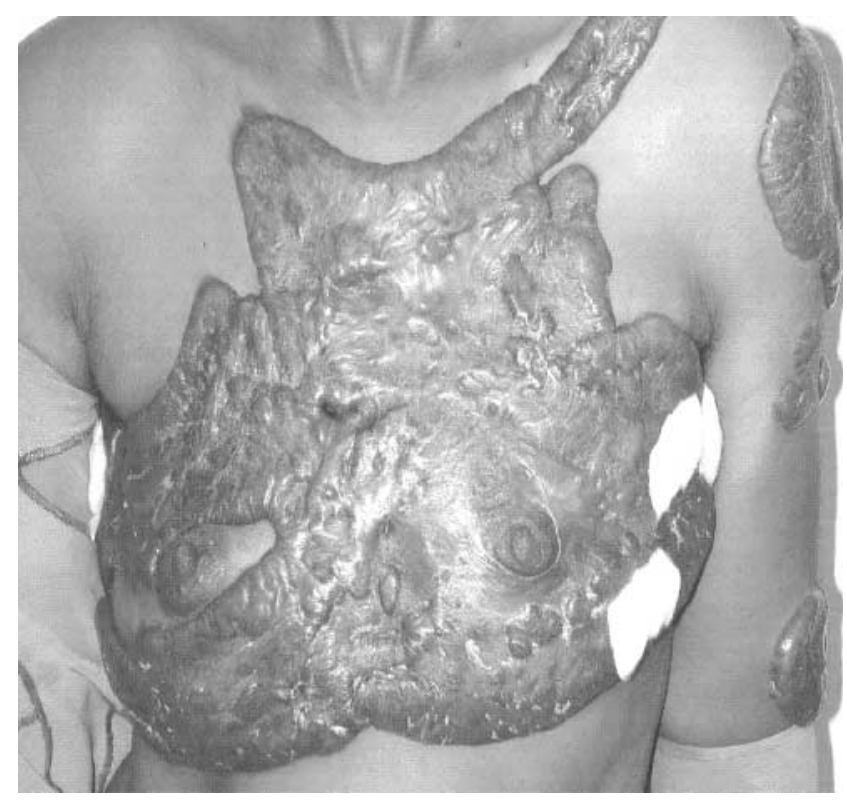

Figure 1 Keloid scarring on chest, case 2 